\title{
WINTER SPORTS INJURIES
}

Leone Coolahan*, Judith E Jones ${ }^{+}$, SC Fung ${ }^{+}$David Lyle ${ }^{+}$ * South Eastern Public Health Unit

+ Epidemiology Branch, NSW Health Department

Ceveral hundred thousand people visit the Australian Alps in southern NSW and Victoria each winter. Many of these people participate in snow sports such as downhill skiing, cross-country skiing, snowboarding and tobogganing. The popularity of snow sports carries a significant risk of injury and possible disability ${ }^{1,2,3,4,5,6,7}$ and as such is a focus of injury prevention action.

In Australia since the early 1960 s records have been kept of snow sports injuries treated at the Perisher Valley Medical Centre, which provides a medical service for several of the major NSW snowfields. The centre's records have been used to provide information on the types and relative frequency of injury $8,9,10$.

In 1992 the South Eastern Public Health Unit combined with the Perisher Valley Medical Centre to extend the scope of routine injury surveillance by capturing additional information on the causes and circumstances of snow sports injuries using the National Injury Surveillance Unit's Injury Surveillance Information System (ISIS) data collection form. The ISIS form collates information from the patient and attending health professional. The patient answers questions about when and where the injury occurred, what the person was doing at the time, what went wrong, what actually caused the injury and the use and functioning of equipment (see Figure 3). The health professional reports on the nature of the injury.

The surveillance initiative complemented changes made to the Inpatient Statistics Collection in 1989 which provide more detailed information on sports injuries, including those resulting from skiing.

This article takes advantage of these two recent enhancements in injury surveillance information and reports on the occurrence and outcomes of snow sports injuries in NSW since 1987. Rates will not be reported here because of the lack of a good denominator ${ }^{11}$.

Three aspects of surveillance data are reported:

the number and nature of snow sports injuries treated at the Perisher Valley Medical Centre between 1987 and 1992, and a small number of patients injured at Thredbo and Mt Selwyn resorts ${ }^{12}$; the number and nature of skiing injuries treated in NSW hospitals between 1989 and 1993; and a review of downhill skiing injuries using data from the ISIS set up at Perisher Valley in 1992.

\section{OUTPATIENT TREATMENT AT PERISHER VALLEY 1987-1992}

During the six years 9,737 injuries were treated at the clinic - an average of 1,623 per season (range 1,451 to 1,834 ). The pattern of injury varied according to age and sex, with 48 per cent of injuries being sustained by men, 38 per cent by women and 14 per cent by children (i.e. under 14 years).

The nature of the snow sports injuries and body parts affected remained relatively stable over the six years.

\section{FIGURE 3}

THE MECHANISM OF

SNOW SPORTS INJURIES

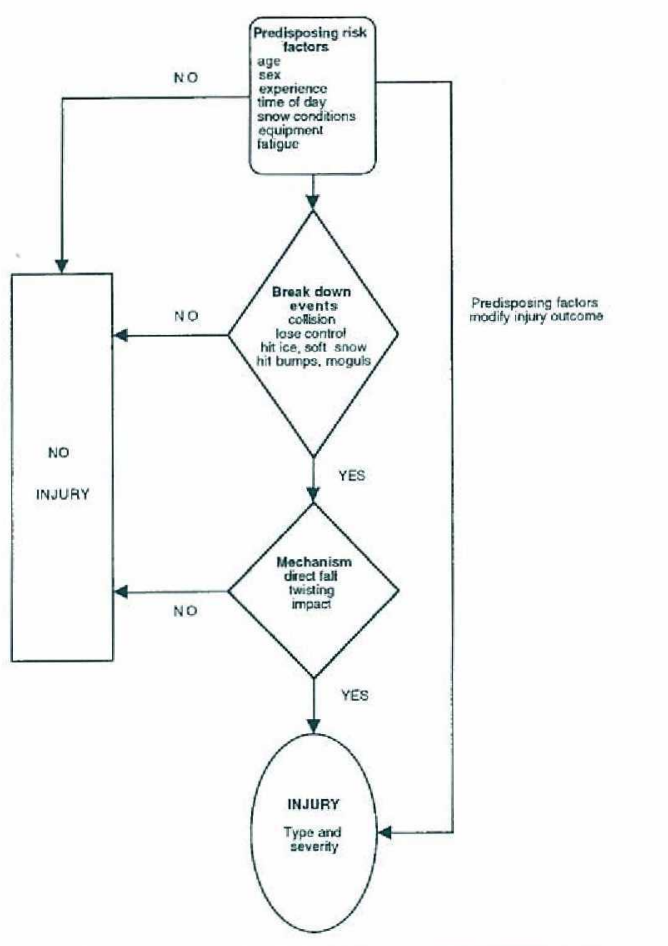

Knee sprain was the most common injury ( 31 per cent of cases), followed by general bruising/haematomas ( 10 per cent) and laceration to the head and face ( 8 per cent). There was a significant increasing trend in the proportion of knee injuries which were isolated anterior cruciate ligament (ACL) injuries $\left(x^{2}=4.76 ; \mathrm{P}=0.03\right)$ and isolated ACL injuries were more likely to be rated as serious than any other single knee injury.

Each year there was an average of one skull fracture (from 35 head injuries), four cervical spine fractures and six fractures to other spinal vertebrae.

Most injuries (93 per cent) were related to downhill skiing, 3 per cent to tobogganing, 2 per cent to cross country skiing and 2 per cent to snowboarding. Snowboarding injuries increased over the period; the first three cases appeared in 1988 , rising each year to reach 6 per cent of all cases in 1992.

Among those seeking treatment for downhill skiing injuries, knee injuries were most common, especially among women. Compared with adults, lower limb fracture and general bruising were more important for children. Men were more likely to have dislocated shoulders and lacerated legs than women or children (Table 2).

Women who rated themselves as experienced skiers had fewer knee sprains (25 per cent) and more thumb sprains (11 per cent) than all injured women (41 per cent and 6 per cent respectively).

Forty-three per cent of snowboarding injuries were fractures to the upper or lower limbs. For tobogganers, back and neck injuries were most prevalent ( 29 per 
TABLE 2

INJURIES DUE TO DOWNHILL SKIING - 1987-1992

\begin{tabular}{|c|c|c|c|c|c|c|c|c|}
\hline \multirow[t]{2}{*}{ INJURY } & \multicolumn{2}{|r|}{ MALES } & \multicolumn{2}{|c|}{ FEMALES } & \multicolumn{2}{|c|}{ CHILDREN } & \multicolumn{2}{|r|}{ PEOPLE } \\
\hline & No. & $\%$ & No. & & No. & & No. & \\
\hline Knee sprain & 1093 & 24.8 & 1465 & 41.0 & 223 & 25.3 & 2781 & 31.4 \\
\hline Laceration head and face & 428 & 9.7 & 197 & 5.5 & 75 & 8.5 & 700 & 7.9 \\
\hline Fracture lower limb & 188 & 4.3 & 141 & 3.9 & 130 & 14.7 & 459 & 5.2 \\
\hline Sprained thumb & 247 & 5.6 & 195 & 5.5 & 21 & 2.4 & 463 & 5.2 \\
\hline Fractured upper limb & 170 & 3.8 & 182 & 5.1 & 48 & 5.4 & 400 & 4.5 \\
\hline Laceration to leg & 313 & 7.1 & 47 & 1.3 & 18 & 2.0 & 378 & 4.3 \\
\hline Dislocated shoulder & 292 & 6.6 & 80 & 2.2 & 3 & 0.3 & 375 & 4.2 \\
\hline Back/neck injury & 173 & 3.9 & 159 & 4.4 & 28 & 3.2 & 360 & 4.1 \\
\hline Head injury/concussion & 129 & 2.9 & 132 & 3.7 & 41 & 4.6 & 302 & 3.4 \\
\hline Shoulder sprain & 191 & 4.3 & 106 & 2.9 & 7 & 0.8 & 304 & 3.4 \\
\hline Ankle sprain & 86 & 1.9 & 90 & 2.5 & 40 & 4.5 & 216 & 2.4 \\
\hline General bruise /haematoma & 368 & 8.3 & 369 & 10.3 & 141 & 16.0 & 878 & 9.9 \\
\hline Other & 728 & 16.5 & 406 & 11.4 & 106 & 12.0 & 1240 & 14.0 \\
\hline Totals & 4406 & 100.0 & 3569 & 100.0 & 881 & 100.0 & 8856 & 100.0 \\
\hline
\end{tabular}

cent); one-third of toboggan injuries were sustained by children.

\section{HOSPITALISATIONS IN NSW 1989-1993}

Over a five-year period there were 1,444 admissions to NSW hospitals for skiing injuries, an average of 289 admissions a year. This probably underestimates the number of hospitalisations because of imprecise coding definitions for 'current' versus 'old' injuries related to Ecodes. Men comprised 52 per cent, women 41 per cent and children 7 per cent of admissions. One in five patients was admitted to the nearest hospital - Cooma District Hospital. Almost one-third (31 per cent) were admitted to three private hospitals in Sydney which specialise in orthopaedic procedures.

The predominant injuries among hospitalised patients were sprains and strains ( 28 per cent), limb fractures ( 23 per cent), arthropathies and related disorders (15 per cent) and dislocations (11 per cent).

More than three-quarters ( $N=1,127 ; 78$ per cent) of patients required procedures. For these patients, the common procedures were repair of cruciate ligaments (25 per cent), reduction of fractures ( 24 per cent) and knee arthroscopy (16 per cent). Most procedures were related to knee ( 76 per cent) or lower leg ( 17 per cent) injuries.

\section{REVIEW OF DOWNHILL SKIING INJURIES 1992}

Many factors may influence skiing injury occurrence, type and severity, including experience, snow and weather conditions, fatigue, the use and functioning of equipment and the ski run environment ${ }^{13}$. We examined some of these factors in detail for the main injury-related activity, downhill skiing (90 per cent of the 1,491 injuries).

Knee sprains were the most common injury for males ( 23 per cent) and females ( 37 per cent). When they occurred, people were typically skiing downhill ( 77 per cent) or turning ( 8 per cent). They reported losing control ( 46 per cent) or colliding with a person or object ( 20 per cent). A twisting action caused 90 per cent of knee sprains.

Ski bindings are designed to release when a skier twists severely, reducing the risk of knee injuries. Failure of bindings to release was a contributing factor for 92 per cent of the women's knee injuries (for 63 per cent neither binding released) and 75 per cent of men's knee injuries (for 35 per cent neither released).

A direct fall was the second most important action resulting in injury ( 34 per cent of injuries). It was the main cause of upper limb fractures (men: 78 per cent; women: 79 per cent) and men's dislocated shoulders (85 per cent).

For children, the main injury was the same as for adults - knee sprain (27 per cent). However children were more likely ( 16 per cent) than adults ( 8 per cent) to sustain limb fractures, particularly lower limbs ( 1 in 10 children's injuries). The small numbers precluded further analysis of predisposing factors in children's injuries.

\section{CONCLUSIONS}

Historical data for Perisher Valley Medical Centre confirm there is a significant number of injuries associated with winter sports activities. While surveillance data cannot provide definitive answers to questions about how interacting factors cause injuries or even the relative contribution of those factors, it does provide information about relative changes in injury patterns, and suggests hypotheses about causal mechanisms and opportunities for intervention.

For example, the large and relatively stable proportion of knee injuries among skiers in their data reflects worldwide trends in skiing injury ${ }^{14}$. Similarly, the major contribution of knee injuries to hospital admissions and the increasing proportion of ACL injuries is in line with a continuing worldwide problem of severe ligament tears $^{1.14}$

The more detailed 1992 surveillance data show that knee injuries occur when a skier twists after losing control during "normal" downhill skiing; bindings do not release to prevent the injury and this is particularly so for women. These data suggest several avenues for effective prevention: 


\section{Winter sports injuries}

$\checkmark$ Continued from page 89

Equipment:

- | redesign bindings and ski boots, especially for women;

- review currently used binding adjustment tables, especially for women;

- introduce mechanical testing for torque and adjustment of bindings ${ }^{7.15,16}$ (mechanical testing is mandatory in US retail and rental outlets and is a widespread practice in Europe); and develop standards for ski equipment (at present no standards exist).

Skier behaviour:

- teach skiers what to do to minimise twisting ${ }^{14}$ when they lose control or collide; and

$\square$ maximise fitness and muscle strength through training.

Skiing environment:

- control volume of use of ski runs; and

$\square$ remove obstacles on ski runs or make them more visible/less hazardous.

Skier attitudes:

- | promote skiers' awareness of the importance of fitness, weather and fatigue.

The National Injury Surveillance Unit has included the data in its database of more than 700,000 injuries.

\section{ACKNOWLEDGMENTS}

We thank the following people for their time and assistance with the surveillance and analysis: staff at the Perisher Valley Medical Centre, especially Dr Louis Fenelon and Joan Bird; Dr Stephen Breathour and staff at the Thredbo Medical Centre; staff of the Emergency Departments at Cooma and Tumut District Hospitals; Mount Selwyn Resort, especially Tim Corkhill and Dave
Wilson; and Dr James Harrison, National Injury Surveillance Unit, Adelaide.

1. Bouter LM, Knipschild PG. Causes and prevention of injury in downhill skiing. Phys Sports Med 1989; 17:81-94.

2. Sahlin Y. Alpine skiing injuries. $B r J$ Sp Med 1989; 23:241-244. 3. Johnson RJ, Ettlinger CF. Alpine ski injuries: Changes through the years. Clin Sports Med 1982; I:181-197.

4. Shealy JE. Death in downhill skiing. In Johnson RJ, Mote CD (eds). Skiing Trauma and Safety: Fifth International Symposium. Philadelphia: American Society for Testing and Materials, 1989; 75-81.

5. Shealy JE, Sundman PD. Snowboarding injuries on alpine slopes, in Johnson RJ, Mote CD, Binet MH (eds). Skiing Trauma and Safety: Seventh International Symposium. American Society for Testing and Materials, Philadelphia: 1989; 75-81.

6. Herkowitz H, Samberg C. Vertebral column injuries associated with tobogganing. J Trauma 1978; 18:806-810

7. Bouter LM, Knipschild PG. Causes and prevention of injury in downhill skiing. Phys Sports Med 1989; 17:81-82,87,91-92,94.

8 . Sherry E, Fenelon L. Trends in skiing injury type and rates in Australia. Med J Aust 1991; 155:513-515.

9 Sherry E, Korbel P, Henderson A. Children's skiing injuries in Australia. Med J Aust 1987; 146:193-195.

10. Sherry E, Clout L. Deaths associated with skiing in Australia: a 32-year study of cases from the Snowy Mountains. Med J Aust 1988; 149:615-618.

11. The number of lift tickets sold which is commonly used, does not take into account factors such as weather conditions or the number of hours spent skiing and it may not be relevant to other activities such as snowboarding and tobogganing. There is no usable data available on participation in winter sports activities. 12. Patients were from Perisher Valley, Charlotte Pass, Blue Cow/Guthega and Smiggins Hole. For 1992, it also included patients treated at Mt Selwyn, Cooma or Tumut Hospitals or who attended Thredbo Medical Centre between June 16 and September 23, 1992. 13. Knipschild PG and Bouter L. Risk factors for ski injuries: a crash course in epidemiologic methods with emphasis on comparability in experiments and case-control studies. In American Society for Testing and Materials Skiing Trauma and Safety: Seventh International Symposium. Philadelphia: ATSM 1991. 14. Ettlinger C. What can be done about knee injuries? Skiing 1989 ; Spring:85-87,121.

15. Bouter LM, Knipschild PG, Volovics A. Binding function in relation to injury risk in downhill skiing. Am J of Sports Medicine $1989 ; 17: 226-233$.

16. Feagin JA et al. Consideration of the anterior cruciate ligament injury in skiing. Clinical Orthopaedics and Related Research 1987 ; 216:13-18.

\section{PUBLIC HEALTH EDITORIAL STAFF}

The Bulletin's editorial advisory panel is as follows:

Dr George Rubin, Chief Health Officer, Public Health Division, NSW Health Department; Professor Stephen Leeder, Director, Department of Community Medicine, Westmead Hospital; Professor Geoffrey Berry, Head, Department of Public Health, University of Sydney; Dr Christine Bennett, General Manager, Royal Hospital for Women; Dr Jane Hall, Director, Centre for Health Economics Research and Evaluation; and Ms Lyn Stoker, Manager, Health Promotion Unit.

The editor is Dr Michael Frommer, Acting Director, Outcomes, Research and Development, NSW Health Department.

The Bulletin aims to provide its readers with population health data and information to motivate effective public health action. Articles, news and comments should be 1,000 words or less in length and include a summary of the key points to be made in the first paragraph. Please submit items in hard copy and on diskette, preferably using WordPerfect 5.1, to the editor, Public Health Bulletin, Locked Mail Bag 961, North Sydney 2059. Facsimile (02) 3919232.

Please contact your local Public Health Unit to obtain copies of the NSW Public Health Bulletin. 